\title{
Erratum to: Hermeneutics of Technologically Mediated Listening
}

\author{
Don Ihde, Listening and Voice: Phenomenologies of Sound, Second Edition, SUNY \\ Press, 2007. Hardcover-296 pages $\$ \mathbf{8 6 . 5 0}$; Paperback—296 pages $\$ 33.95$
}

\author{
Arun Kumar Tripathi ${ }^{1}$
}

Published online: 10 April 2017

(C) Springer-Verlag London 2017

\section{Erratum to: AI \& Soc DOI 10.1007/s00146-017-0708-5}

In the original publication, references to Ihde (2008) and Pinch (2002) were missing and incorrectly cited on pages 3 and 4 . The text with corrected citations is provided below.

On the materiality of sound, "its embeddedness not only in history, society and culture but also in science and technology and its machines and ways of knowing and interacting, is a topic which I think is not yet addressed sufficiently by other fields like musicology and the history and sociology of music" (Pinch 2002: 109).

In the case of loss of hearing, hearing horns have been depicted in treatises on the senses for several centuries. However, hearing horns are simply amplification devices, and in most loss of hearing, more is needed than mere amplification. With normal ageing, most people begin to lose certain — usually high-frequencies. In addition, these cannot be restored with amplification. Ihde in the
"Listening and Voice" is describing personal experiences with musical devices. In his late 1960s, Ihde began to notice some hearing problems and noted difficulty hearing questions from the back of the lecture halls and found cocktail party conversation hard to manage. Taking a frequency range test during a conference in Boston at the Science Museum, Ihde found that his hearing was considerably short of the 20,000 cps younger, better hearing could detect (Ihde 2008: 400).

\section{References}

Ihde D (2008) Aging: I don't want to be a cyborg! Phenom Cogn Sci 7:397-404. doi:10.1007/s11097-008-9096-0

Pinch T (2002) Emulating sound: what synthesizers can and can't do: explorations in the social construction of sound. In: Zittel C (ed) Wissen und Soziale Konstruktion. Akademie Verlag, Berlin, pp 109-127
The online version of the original article can be found under doi:10.1007/s00146-017-0708-5.

Arun Kumar Tripathi

tirelessarun@gmail.com

1 Central University of Tibetan Studies, Sarnath, Varanasi, Uttar Pradesh 221007, India 